Nenad Tomić1,

Violeta Todorović ${ }^{2}$,

University of Kragujevac,

Faculty of Economics
ORIGINAL SCIENTIFIC ARTICLE doi:10.5937/ekonomika2001013T

Received: December, 07. 2019.

Accepted: January, 30. 2020.

\title{
POTENTIAL NEGATIVE IMPLICATIONS OF LIBRA CRYPTOCURRENCY
}

\begin{abstract}
Cryptocurrencies have been in the center of interest of both scientific and professional public for over ten years. Due to the volatile exchange rate against convertible currencies, investors predominantly use cryptocurrencies as an instrument of speculative investment, while their use in the payments is at a negligible level. On June 18, 2019, the Internet giant Facebook announced the creation of a consortium of financial and technology companies aimed at establishing a global cryptocurrency with stable value called Libra. It is planned to create an open blockchain through a new programming language, which will serve development teams in the future for creation of smart contracts. The subject of research in the paper will be the potential operational performances of Libra concept. The basis for the research will be a white paper published by Facebook and knowledge about the functioning of other cryptocurrencies, notably Bitcoin. The aim of the paper is to highlight the expected economic and security implications of Libra concept.
\end{abstract}

Keywords: Facebook, Libra, stablecoin, blockchain, smart contracts, reserve fund

JEL classification: E42, O33

\section{ПОТЕНЦИЈАЛНЕ НЕГАТИВНЕ ИМПЛИКАЦИЈЕ СИСТЕМА ЛИБРА}

\begin{abstract}
Абстракт
Крийтовалуйе се налазе у средишйу иниеересовань научне и сирручне

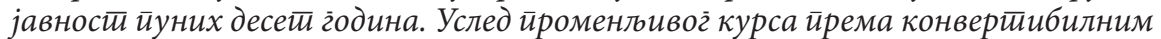

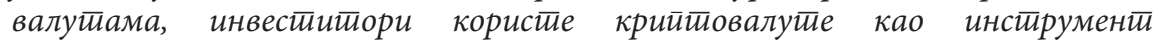
ииекулаиииногі улагана, док је юихова уйоиреба у йлайном иромейу на занемарљиво ниском нивоу. Инитернети гиганй Фејсбук је 18. јуна 2019. године објавио сииваране конзориијума финансијских и иехнолошких комйанија, чији

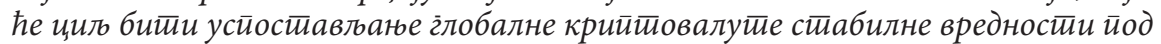
називом Либра. Планирано је сшиваране ошвореног блокчејн кода кроз нови ирогірамски језик, који ће у будућносии служити развојним ииимовима за

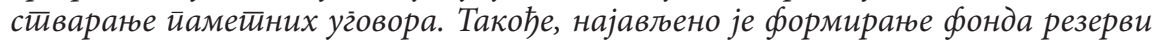

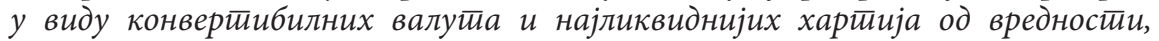

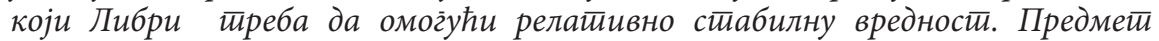

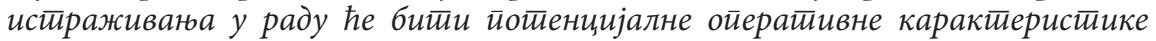

\footnotetext{
${ }^{1}$ ntomic@kg.ac.rs, ORCID ID https://orcid.org/0000-0003-1565-3197

${ }^{2}$ v.todorovic@kg.ac.rs, ORCID ID https://orcid.org/0000-0002-3258-160X
} 
кониеййа Либра. Основу истираживана ће чинити бела книга коју је објавио Фејсбук и знане о досадашюем функиионисану друг̈их крийиовалуйа, у ирввом реду Битикоина. Циь рада је да се укаже на очекиване економске и сигурносне имйликаиије овог кониеййа Либра.

Keywords: Facebook, Libra, stabilna kriptovaluta, blokčejn, pametni ugovori, fond likvidnih rezervi

\section{Introduction}

Since the advent of Bitcoin in January 2009, cryptocurrencies have been in the focus of interest of the academic public. Their infrastructure is based on blockchain, cryptographical technology that enables the decentralized government of large databases (Nakamoto, 2008). A decentralized management system and the opportunity for large profits from speculative transactions have attracted a large number of investors. Over the ten years of their existence, more than 1,000 different forms of cryptocurrencies have been registered, with a total market capitalization exceeding US \$ 300 billion (coinmarketcap. com). Notwithstanding the above, cryptocurrencies do not take a significant share in the modern payment system.

On June 18, 2019, the Internet giant Facebook published a white paper outlining the company's strategic commitment to developing a new cryptocurrency called Libra (libra. org). Two key differences over Bitcoin and the largest number of other cryptocurrencies were announced. First, the coin emission will not be controlled by a pre-programmed algorithm, but by a central institution. Second, the goal is to make Libra a stablecoin, or cryptocurrency that will have a relatively stable value against the basket of convertible currencies. A stable value would help it avoid frequent speculative transactions, which affect the capricious movement of the value of other cryptocurrencies. The above should make Libra more attractive for use in payment transactions.

The subject of this paper is potential operational performances of the Libra concept. The basis for the research will be a white paper published by Facebook and knowledge about the functioning of other cryptocurrencies, notably Bitcoin. The aim of the paper is to outline the expected economic and security implications of Libra concept. The first section of the paper will analyze the technological basis of the future system. In the second section, based on the existing knowledge of cryptocurrencies, some conclusions will be drawn about possible economic effects. The negative implications for personal security and data privacy will be presented in the third part of the paper.

\section{The technological basis of Libra concept}

The White Paper was signed by 53 authors, including a significant number of academics in the fields of information technology, artificial intelligence and payment systems. Its primary statement is about the insufficient and unequal financial inclusion in the world, which affects about 1.7 billion adults. It is an underdeveloped part of the world, where basic payment services are unavailable or more expensive than in the developed parts. As can be seen in Figure 1, the availability of financial services in the mentioned 
countries is lower than the availability of internet and mobile telephony, so it is clear that the technological infrastructure can be used to increase financial inclusion.

Figure 1: Number of adults with access to mobile telephony which do not possess a bank account (in millions, data from 2017)

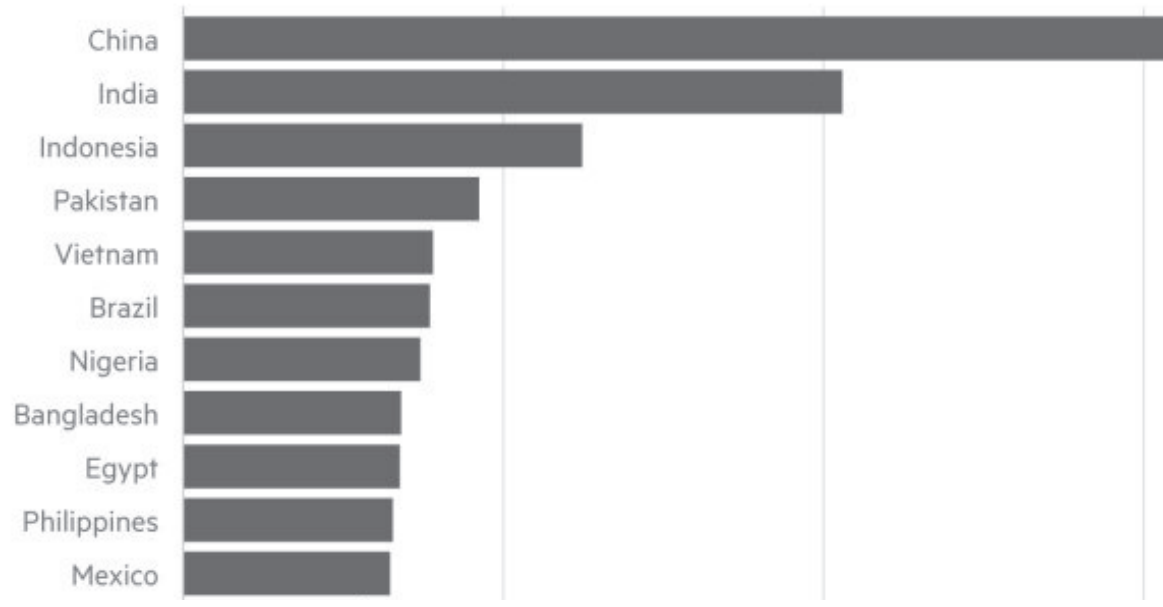

Izvor: Demirgüç-Kunt et al., 2018

It is proposed to create a single payment system that will enable fast and cheap transfer of global electronic money based on blockchain technology. The system was named Libra and it is expected to become operational in the first half of 2020. The three pillars should underpin the functioning of the overall concept:

1. System is governed by independent Libra Association, whose mission is the initiation and development

2. Blockchain technology is the basic of the system

3. Money value is backed by the liquid asset reserve fund

1) Libra Association will be a non-profit organization based in Geneva. Its members are recognizable companies from different business sectors. At the time White Paper was published, the Association had 28 founding members, with a goal to have 100 by the start of the system. Alongside Facebook, the founding members are Visa, MasterCard and PayPal from payment institutions, Vodafone from telecommunications companies, eBay and Lyft from the internet megastores, Coinbase and Xapo Holdings from blockchain companies, Spotify and Uber from service companies, Thrive Capital, Union Square Ventures and Adreessen Horowitz from venture capital funds, etc.

The founding members have an obligation to bring together new members of the Association, to provide a sufficiently large market through merchant-oriented acceptance programs for Libra, and to provide funding for the system initiation. Each founding member was required to pay at least \$ 10 million through the purchase of the so-called investment token. Once the system is up and running, the members of the Association will play the role of nodes in the blockchain network, which means they will control and 
validate the transactions. The principle that each investment token gives one vote in the validation process will apply, with limitation of maximum votes that an entity can hold. This will prevent the concentration of controlling power, so neither Facebook nor any other institution could have a privileged position. The aim is to create conditions within five years for participants who have not purchased an investment token, but who own a larger amount of Libra coins, to be included in the validation process. Consequently, the algorithm would become open proof-of-stake (Li et al. 2017).

The Association will make all key operational decisions through the Council, in which, similar to the validation process, each member will poses votes in proportion to the investment tokens it owns, with a limited maximum votes. All technical decisions and decisions concerning reserve fund will have to be made by a two-thirds majority, while other decisions will be made by a majority vote. The operational management of the Association will be taken over by a board, which will consist of between four and eighteen representatives of the members of the council in addition to the elected executive director.

2) Blockchain is a cryptographically authenticated database (Zheng et al. 2017). Based on one of the consensus protocols, authorized participants - nodes - can modify its content. In the case of cryptocurrencies, the database refers to the ledger of all transactions - it contains a list of all participants and the amounts of coins in their possession. The new transaction $T_{i}$, occurring at one point in time, must be in accordance with the previous records $S_{i}$ in the sense that the payer has sufficient funds in his account. If the nodes confirm the validity of the transaction, the changes it creates will become part of the new state of the ledger $S_{i+1}$.

The basis of Libra blockchain technology is the Move programming language. It is a new programming language, enabling open source smart contracts to be created (Nelaturu, 2019). For the purpose of its creation, previous experience with smart contracts has been used, especially situations where programming failures have occurred. Move will allow the creation of digital assets under the same principles that applies to physical assets: an object has only one owner, it can be consumed only once, and cannot be duplicated. Only certain entities (Association) have the ability to create new copies of assets.

Each account address will be a 256-bit record. Opening an account and signing transactions will be based on a pair of public key (pk) and a private cryptographic key (sk). Applying the hash function SHA3-256 to the public key a $=\mathrm{H}$ (pk) gives the account address (Group of authors, 2019). The EdDSA private key digital signature method will be used for signing transactions. Account addresses are pseudonyms and cannot be linked to customer's real identity. It will be possible to open more than one account with no direct link indicating that the owner is the same customer. A transaction fee is charged for the execution of the transaction to prevent the network from being exposed to DDoS attacks (Constine, 2019).

Byzantine fault tolerance (BFT) approach will be used to reach consensus between nodes. With BFT, consensus on transaction validity can be reached even in situations where up to one-third of the nodes behave maliciously - whether it is a hacking attack or a hardware malfunction (Lamport, Shoshtack, \& Pease, 1982, p. 383). The basic idea when choosing a protocol was the ability to expand the base of nodes in the later stages of system functioning and scalability in terms of the number of transactions. Proof-of- 
work protocols have not been considered at all because of the high energy consumption of validation (Todorović \& Tomić, 2019, p. 52).

3) Libra is planned to be a global cryptocurrency with a stable value, fully covered by reserves in financial assets. The existence of real cover is a fundamental difference from all previous cryptocurrencies. At any time, customers will be able to sell their Libra stock for the desired convertible currency at a pre-known exchange rate. However, this rate will not always be fixed, as Libra will not adjust to any particular currency, but rather a basket of stable and liquid assets. In addition to the most stable currencies in the world, the basket will also contain treasury bills and certificates of deposit from the same countries. The change in the value of these assets will change the exchange rate of Libra. The revenue generated by the assets in the reserve fund will be used to cover the costs of developing and upgrading the system or paid as dividends to the early investors. The revenue sharing scheme will be known and announced in advance.

There are two sources of reserve funds: the purchase of investment tokens and the purchase of new Libra coins. In order to create a new quantity of Libra coins, it is necessary that customers buy them with their convertible money, thus increasing the reserves. The number of coins in circulation decreases, when customers sell their Libra coins to Association. At the same time, the liquid assets in Libra Reserves also decrease. In that manner, the Libra Reserve will serve as the "buyer of last resort". The Association will not conduct monetary policy through the Libra Reserve, nor will it create new quantities of Libra coins that are not backed by reserves.

\section{Potential economic effects}

The realization of the mentioned plans would bring certain economic advantages. This primarily refers to the financial inclusion of clients from developing countries. The clients from countries that do not have a sufficiently extensive banking network due to large territories, such as India and Nigeria, would particularly feel the benefits. In a number of countries the internet is more accessible than banking services. The users without access to banks would thus be able to send and receive money internationally. To fully grasp the potential effects of the Libra concept, it needs to be understood not just as a new cryptocurrency, but as an entire economic ecosystem. Libra will offer more than global electronic money, primarily through the provision of open source to create and execute smart contracts.

Smart contracts are contracts that are self-executing on the basis of the terms entered in the program code (Szabo, 1997). Terms are visible through the code on the public blockchain network. Their use enables automatic execution of the transaction at the moment of fulfillment of the set conditions, without verification and confirmation by the central institution. Transactions are public and non-refundable. The implementation of smart contracts will be possible not only in business, but also in medicine and transportation. Their full implementation requires a large amount of digital data, which will be provided by the Internet of Things (IoT) in the future. Facebook and other members of the Association hope that by creating a reliable and open platform for smart contracts, it will attract a large number of users, who will use Libra to execute smart contracts. 
Unlike Bitcoin, Libra will have centrally controlled issuance and relatively stable value. Both solutions have already been seen in some cryptocurrencies and are no surprise, but the way they are implemented is innovative. First of all, the institution that controls the system is not an anonymous technology company without reputation. Facebook itself, including Instagram and WhatsApp, has 2.38 billion active users (Noyes, 2019). The analysis of the founding member list shows that they were carefully selected in order to maximize the number of users of different profiles. The obvious motive is to highlight recognizable companies in key market niches where prospective customers should be sought. This could solve the basic problem of all electronic money systems since the mid-1990s - the formation of a critical mass of customers.

The idea that the value of Libra is not tied to a single currency, but a basket of liquid assets solves the problem of the optimal currency area that other stablecoins have encountered (Mundell, 1961). The real novelty is the reserve fund, which enables full coverage of coins in circulation with liquid assets. This will be the first case that cryptocurrency will have intrinsic value. It is believed that the Libra Reserve could contribute to customer confidence and a willingness to hold Libra stocks for longer periods. Therefore, by properly approaching the problem of centralization and currency stability, the Association will first be able to quickly form a large customer base and provide a high amount of cryptocurrency in constant circulation.

Provided that these two conditions are met, a large amount of convertible currencies could be paid into the reserve fund in the short term. The longer the average customer is willing to hold Libra coins, the more it will be possible to hold assets in liquid securities that create revenue. Buyers of the investment token will earn an annual dividend on this basis. So, while the Association itself is a non-profit organization, the companies that make it are primarily oriented at making profit. It is clear that companies that buy an investment token want to make a profit, but it raises the question of compliance with the mission of the project. The authors of the White Paper emphasized at the outset that the mission of Libra is the financial inclusion of clients from less developed parts of the world. Consortium members will endeavor to charge on a continuous basis for enabling inclusion. The first problem that arises is of an ethical nature: why are multinational companies, each worth billions of US dollars, hiding behind helping the underdeveloped population of the world in a new project, when it is clear that generating profit is the goal?

The following problem is closely related to the first one. The White Paper stated that the Libra Reserve would not trade directly with customers, but would transact through special resellers authorized by the Association. There is no further information on who will be authorized resellers or what criteria they should meet. Since there are companies that have the capacity to perform payment services among the founding members (Visa, MasterCard, PayPal), will the role of resellers be entrusted to them? Who will be able to contest for the license, if resellers should be brand new institutions? How much fee will resellers charge for their own services? Is this a way for founders, or some of them, to make additional profits that will actually be shown as operating expenses? These questions do not have an answer, but they provide a basis for looking at the whole concept from a different perspective.

Assuming Libra is widely used in developing countries, the question of the ability of central banks to implement monetary policy arises. The topic of the impact of electronic money on monetary policy is not new, but past considerations have led to the conclusion that central banks are not yet endangered. The first isolated example of the impact of 
electronic money on real economic flows was recorded in 2013, when introducing state control of bank deposits in Cyprus (Cohan, 2013). A more striking example was noted in Venezuela in 2018, when a large number of citizens were buying cryptocurrency Petro due to hyperinflation (Osborne, 2018). Therefore, it is possible that once Libra becomes operational, a large number of developing country citizens transfer their liquid assets to the new cryptocurrency. The motives for this act may be volatility of the domestic currency, an underdeveloped network of banking services, the desire for frequent crossborder payments without the high fees and costs of currency conversion, or hiding from regulatory authorities. The consequence will be the inability of central banks to influence economic developments by monetary policy measures, since the measures will refer to currencies used by too few citizens. These risks do not threaten one country or countries in one region, but practically the whole world. The possibility of losing monetary control is far lower with the Fed or the ECB than with African or Asian central banks, but there is already an opinion among politicians and experts that the institution that governs Libra should be registered as a bank.

The authors of White Paper stressed that the Association has no ambition to conduct monetary policy. As such statement is not legally binding, there is no guarantee that the ambition will not arise in the future. However, there are already two fundamental problems with this statement. Firstly, the fact that the Association forgoes the opportunity to conduct monetary policy in advance means that there are already plans for such growth that will give it the ability to conduct monetary policy. Secondly, the question is how the Association defines monetary policy. If the payment system of one or more states relies heavily on Libra so that national central banks lose the ability to influence the economy by their own measures, then any decision coming from the Association will actually have monetary policy effects.

The great financial potential will create the danger of transforming Libra Reserve into a huge shadow bank (Hamilton, 2019). The White Paper does not explicitly state the future relationship with credit activities, which does not mean that the Association does not think about it. If, based on the financial potential gained by issuing Libra coins, the Association starts lending, it would directly influence the growth of money supply of those currencies in which the loans would be denominated. Moreover, this would actually be a form of monetary policy. Knowing that the profit is the sole motive for members of the Association, it is difficult to expect that in the future the funds will not be directed to achieve higher yields than those made by treasury bills.

In recent years, cryptocurrencies have been considered risky in terms of money laundering and terrorism financing. The fact is that cryptocurrencies have been used to fund illegal activities due to the high level of anonymity they provide. In October 2013, the FBI raided Silk Road, an internet stock market of weapons, narcotics, stolen credit cards and other illegal goods, which was using Bitcoin as a mean of payment (Van Hout \& Bingham, 2013, p. 387). Following the shutdown of the site, several copies were created, on which the most commonly was used cryptocurrency Monero in addition to Bitcoin (Greenberg, 2017). It is also recorded that the distribution of computer viruses known as ransomware, which lock the operating system of the victims until the ransom is paid in cryptocurrency, most commonly Bitcoin, becomes more frequent (Armerding, 2019).

However, it is not possible in practice to measure the extent of the use of cryptocurrencies for criminal purposes. The mere fact that they are suitable for money 
laundering and terrorism financing does not necessarily mean that this will be the primary sphere of their use. Based on some estimates, the use of cryptocurrencies for criminal purposes is far lower than their use for speculative investments. It is believed that Libra would simplify the infrastructure for a large number of criminals. There is growing concern in Europe and the US about the use of electronic money for criminal purposes. The European Parliament has adopted the Fifth Anti-Money Laundering Directive (Directive 2018/843), which deals specifically with cryptocurrencies and prepaid cards. Electronic exchanges and digital wallet companies are required to be able to identify users. Through the 2001 Patriotic Act, the United States made mandatory the identification of payment service clients and abolished banking secrecy in a number of cases. Facebook has previously stressed that the plan for Libra is to comply with all existing regulations. The problem is that there will be no financial inclusion in this case, as compliance with customer identification and anti-money laundering laws prevent the inclusion of people who do not have access to the banking infrastructure for any reason - geographical, legal or cultural (Coppola, 2019). For the full financial inclusion already discussed, Libra would have to circumvent certain legal solutions.

\section{Privacy and security implications}

When discussing contemporary payment trends, the possibilities of ending the use of cash and developing electronic money that will become the standard in transactions are often emphasized. There are different opinions about whether one or more countries will develop their own national electronic currencies, or whether a consortium of corporations will try to introduce a single global electronic currency. The Libra is precisely the realization of the second concept. While the economic arguments regarding fast and global transactions are undeniable, there are numerous uncertainties and potential issues with regard to customer security.

There are two misconceptions that cause most customers to be overtly open to new technology. The first is the belief that new technology necessarily brings higher efficiency and security and lower costs of use. The second refers to the view that technological development is linear, so that it is necessary to adopt all available innovations to create a society of the future. Both assumptions are wrong. The factors listed in the first assumption often have inverse relation. There are numerous examples of technologies that truly deliver higher efficiency and/or security, but never experience commercial application due to high costs. Those that reduce costs or speed up process execution can increase the instability of the environment. Even with the unchanged likelihood of an adverse event occurring, the higher amount of potential loss makes the application of new technology socially undesirable. Technological progress is chaotic and unpredictable, so abandoning one innovation does not diminish the possibility of progress in other areas. Examples are the old South American civilizations that have developed astronomy more advanced than any Eurasian civilization, although they did not have a developed monetary system or know the wheel technology.

The previous can be applied to contemporary payment trends. The use of cash has numerous disadvantages, such as the cost of transportation, safekeeping and storing, the physical damage of the banknotes, the use of it in criminal activities, the inappropriateness for long-distance payments, and the transfer of bacteria. Nevertheless, 
all these shortcomings are known in advance. Users and regulatory authorities have more or less ready mechanisms to combat deficiencies and are prepared for their emergence. A cashless world offers some economic benefits as well as a number of potential problems. The authorities have no answer to these problems, nor are customers ready to face them. For this reason, their effect can be devastating, not only on economic flows, but also on personal freedoms. Demolishing the institutional foundation built over centuries, with the establishment of an untested and unreliable system, can lead to unprecedented consequences. Global electronic moneys would give complete control over economic life to states (if they were national cryptocurrencies) or multinational corporations (if Libra or some similar private cryptocurrency would become globally acceptable).

It is stated in the White Paper that accounts will be pseudonyms, and that it will not be possible to link them with the customer's real identity. So Libra will reportedly be anonymous. One could rightfully doubt the truth of this claim. Earlier cryptocurrency experiences indicate that anonymity is only viable in the case of isolated transactions within a smaller circle of customers (Hodgson, 2018). With increasing frequency and number of partners in transactions, the chances of losing anonymity grow exponentially. Given that the ledgers of most cryptocurrencies are publicly available, the regulatory body or any interested party can easily track all accounts with which a disputed account has performed transactions. It is sufficient to anyhow identify only one of those participants, after which others can be identified by monitoring his transactions. Thus, the anonymity offered by cryptocurrencies is not one hundred percent, and its disruption depends on the persistence of the government identify the transactors. In the case of Libra, it may even be easier and faster to identify customers.

Facebook has announced the creation of an official digital wallet called Calibra, designed to execute Libra-denominated transactions. While it is emphasized that the Calibra wallet will be available as a separate application, unrelated to social media accounts, an opportunity install it as an add-on to WhatsApp or Messenger has also been left. This is the information that creates more doubt than the topic of monetary policy management. Facebook is known for monetizing its users' data. On social networks, companies can pay to use demographic information of users in advertising management, for more accurate targeting in marketing campaigns. Little less is known that Facebook sells users' data to analytics companies, which can later use it for any purpose (Newton, 2018). The fact that a company entrusted by users with a piece of personal information for entertainment purposes makes money from the sale of that information sounds unacceptable by itself. Even if data buyers only intend to market their own products, the problem persists. Users will receive advertisements that they did not want, for products they are not interested in. Data buyers' desire to influence users' political attitudes or to create discriminatory profiles on any basis, are also realistic options. In addition to the fact that Facebook was not interested in the purpose of the data sold, the absence of accepting responsibility in the situation when the sale became publicly known should be added. In July 2019, Facebook, Instagram, and WhatsApp became temporarily unavailable for adding new photos and viewing existing ones. After eliminating the problem, the management in no way wanted to comment on the reasons for its occurrence (Vaughan-Nichols, 2019). This indicates that this company should not be trusted, nor social responsibility should be expected. Facebook is a perfect example of a company which does not address its growing reputation risk (Tomić \& Sedlarević, 2014, p. 170). 
If Libra becomes a global payment system, Facebook will be able to add through Calibra the latest set of information that has not been collected through social networks - its users' payment history. Facebook has promised not to link users' network profiles to payment accounts, but the promise is not legally binding. This is why the claim of account anonymity seems completely unconvincing - transactions may be anonymous to everyone else, for Facebook it certainly won't be. Since it is previously known that it often made available information to government agencies, this means that the US government will be able to track users' payments on demand. At the same time, Facebook will receive another segment for monetizing data.

Determining the difference between the potential benefits and losses of the application of new technology is particularly difficult in a contemporary context, when privacy losses outweigh financial losses. The question is not whether the user has anything to hide from others, but whether others, having complete information about him, will be able to harm him. Aggressive promotional campaigns daily marketed to compulsive buyers are just one option. The system can temporarily or permanently block funds for politically ineligible users, and on the basis of payment history, form patterns of persons posing a security threat. Of course, it is quite by chance that such patterns can identify individuals who pose no threat. If Libra becomes a global mean of payment, it will be possible for a company with a rich history of information abuse could also make lists of non-eligible persons.

\section{Conclusion}

Previous considerations include available knowledge of cryptocurrencies and Facebook's business model, but they generally represent no more than assumptions of future development. In order to discuss the future of the Libra concept, it first needs to become operational. Certain blockchain experts tested the code they received from Facebook and proved that it still does not work. So the Libra concept may not become operational in the near future. In the event that this does happen, there are three possible outcomes.

The first one refers to the situation where Libra would become just another part of the cryptocurrency mass. Its stable value would make it unsuitable for speculative investments, which currently make up by far the largest percentage of all cryptocurrency transactions. Facebook's previous irresponsible behavior would make it undesirable for conservative customers. Cryptocurrency supporters would turn even further to Bitcoin and its surrogates, rejecting fully centralized and controlled cryptocurrency. Under these conditions, Libra would not have a significant market share.

The second one relates to the situation in which Libra would take the lead among on cryptocurrency market. Recognizable founding members would implement programs to support the Libra's early adoption. Companies would reward customers for certain marketing activities with Libra coins which cannot be exchanged for convertible currencies but only spent. Members would begin to offer certain services exclusively for Libra payments. Many online retailers would begin to accept Libra payments, considering them competitive advantages. In this case, too, Libra would not become a truly global mean of payment. Residents of developing countries would have nowhere to 
spend Libra, so they will only serve as a means of transferring money among separated family members, as the transfer will be cheaper than through Western Union. Residents of developed countries would lack one final stimulus for full acceptance. Amazon and Alibaba would never accept Libra, which would permanently make it less competitive than PayPal in e-commerce.

The third outcome relates to the global use of Libra. Influenced by the virality of mass use, all the largest online retailers would integrate into its ecosystem. Before starting, Amazon and Alibaba could become part of the Association. In developing countries such as India, Indonesia, Pakistan and Nigeria, a large number of retailers would accept Libra through mobile phone application. The expansion of smart contracts in the future would give an additional impetus to the use of Libra.

In the second or third case scenario, countries would have to respond by regulating the system. The fact is that Libra does not aim to crowd out the dollar or the euro, because it needs those currencies to have a stable value. Without strong convertible currencies, the Libra has no value. However, it is also clear that the motives of the Association are not well-intentioned as claimed in the white paper. The goal is not to influence the monetary policy of developing countries either, but it should not be expected that the Association will endeavor to avoid this situation for ethical reasons only. The only goal that members of the Association follow is profit. In line with the high investments that the whole concept will require, one should expect that the founding members are prepared on anything just to make a desirable profit. That is why the users are the ones who have the ability to prevent the implementation of a mechanism for global control of payment information.

\section{References}

Armerding, T. (2019). Get Ready For A Ransomware Tsunami. Forbes, July $3^{\text {rd }}$

Cohan, P. (2013). Are Bitcoins safer than Cyprus?. Forbes, April $2^{\text {nd }}$

Constine, J. (2019). Facebook announces Libra cryptocurrency: everything you need to know. Techcrunch, June $18^{\text {th }}$

Coppola, F. (2019). The Real Threat From Facebook's Libra Coin. Forbes, June $30^{\text {th }}$

Demirgüç-Kunt, A., Klapper, L., Singer, D., Ansar, S., \& Hess, J. (2018). The Global Findex database 2017: Measuring financial inclusion and the fintech revolution. World Bank Group

Greenberg, A. (2017). Monero, the drug delaer's cryptocurrency of choice, is on the fire. Wired, January $25^{\text {th }}$

Group of authors (2019). The Libra Blockchain, available at: https://developers.libra. org/docs/assets/papers/the-libra-blockchain.pdf

Hamilton, I. A. (2019). Mark Zuckerberg's 'shadow bank': The pushback against Facebook's new cryptocurrency has already begun. Business Insider, June $18^{\text {th }}$

Hodgson, C. (2018). Crypto expert: The anonymity of cryptocurrency users may not last forever. Business Insider, January $6^{\text {th }}$ 
Lamport, L., Shoshtak, R., \& Pease, M. (1982). The Byzantine generals problem. ACM Transactions on Programming Languages and Systems. 4(3), 382-401

Li, W., Andreina, S., Bohli, J.M., \& Karame, G. (2017). Securing Proof-of-Stake Blockchain Protocols. In J. Garcia-Alfaro, G. Navarro-Arribas, H. Hartenstein, \& J. Herrera-Joancomarti (eds.) European Symposium on Research in Computer Security International Workshop on Data Privacy Management Cryptocurrencies and Blockchain Technology (pp. 297-315), Oslo, Norway

Mundell, R. A. (1961). A Theory of Optimum Currency Areas. American Economic Review, 51(4), 657-665

Nakamoto, S. (2008). Bitcoin: A peer-to-peer electronic cash system, available at: http:// Bitcoin.org/Bitcoin.pdf

Nelaturu, K. (2019). Overview of Move Programming Language. Medium, July $4^{\text {th }}$

Newton, C. (2018). Why we can't stop debating whether Facebook sells data. The Verge, December $14^{\text {th }}$

Noyes, D. (2019). The Top 20 Valuable Facebook Statistics - Updated July 2019. Zephoria, July

Osborne, C. (2018). Trump bans Venezuela's cryptocurrency Petro in the US. ZDNet, March $20^{\text {th }}$

Szabo, N. (1997). Formalizing and Securing Relationships on Public Networks. First Monday, 2(9)

Todorović, V., \& Tomić, N. (2019). Neodrživost koncepta kriptovaluta baziranih na proof-of-work algoritmu. Bankarstvo, 48(1), 46-63

Tomić, N., \& Sedlarević, L. (2014) The evolution of banking risks from traditional to electronic banking, Anali Ekonomskog fakulteta u Subotici, 50(31), 161-175

Van Hout, M.C., \& Bingham, T. (2013). „Silk Road“, the virtual drug marketplace: A single case study of user experience. International Journal of Drug Policy, 24(5), 385-391

Vaughan-Nichols, S.J. (2019). Facebook, Instagram, and WhatsApp repaired without a real explanation. $Z D N e t$, July $5^{\text {th }}$

Zheng, Z., Xie, S., Dai, H., Chen, X., \& Wang, H. (2017). An Overview of Blockchain Technology: Architecture, Consensus, and Future Trends. In G. Karypis, \& J. Zhang (eds.) 6th IEEE International Congress on Big Data (pp. 557-564), Honolulu, HI

\section{Internet sources}

https://coinmarketcap.com/all/views/all/ (accessed on November $11^{\text {th }} 2019$ )

https://libra.org/en-US/white-paper/ (accessed on November 10 ${ }^{\text {th }} 2019$ ) 